\title{
Strontium ranelate analgesia in arthritis models is associated to decreased cytokine release and opioid-dependent mechanisms
}

\author{
Rodolfo de Melo Nunes ${ }^{1} \cdot$ Morgana Ramos Martins $^{1} \cdot$ Francisco Saraiva da Silva Junior $^{1} \cdot$ \\ Ana Caroline Rocha de Melo Leite ${ }^{1}$ - Virgínia Claudia Carneiro Girão ${ }^{2}$. \\ Fernando de Queiroz Cunha ${ }^{3}$. Aryana Lushese Lima Feitosa Marinho ${ }^{1}$. \\ Ana Carolina Matias Dinelly Pinto ${ }^{1} \cdot$ Francisco Airton Castro Rocha $^{1}$
}

Received: 14 April 2015/Revised: 28 July 2015/Accepted: 30 July 2015/Published online: 6 August 2015 (C) Springer Basel 2015

\begin{abstract}
Objective We investigated the anti-inflammatory activity of strontium ranelate (SR) in arthritis models.

Materials and methods Rats received $1 \mathrm{mg}$ zymosan (Zy) or saline intra-articularly. Other groups were subjected to anterior cruciate ligament transection in the right knee, as an osteoarthritis (OA) model, or a sham procedure. Joint pain was assessed using the articular incapacitation and paw-pressure tests. Cell influx and cytokines were measured in joint exudates.

Treatment Groups received either SR (30-300 mg/kg per $o s)$ or saline.

Results SR dose-dependently and significantly inhibited joint pain in both $\mathrm{Zy}$ and OA models, while not altering cell influx. Naloxone administration significantly reversed SR analgesia. SR significantly reduced levels of Interleukin- $1 \beta$ and tumor necrosis factor- $\alpha$ in $\mathrm{Zy}$ arthritis, whereas those of cytokine-induced neutrophil chemoattractant (CINC)-1 were not altered.

Conclusions SR provides analgesia in arthritis that is associated to inhibition of the release of inflammatory
\end{abstract}

Responsible Editor: Jason J. McDougall.

Francisco Airton Castro Rocha

arocha@ufc.br

1 Department of Internal Medicine, Faculty of Medicine, Federal University of Ceará, R. Dr. Jose Lourenco, 1930, Fortaleza, Ceará 60115-281, Brazil

2 Department of Morphology, Faculty of Medicine, Federal University of Ceará, Fortaleza, Ceará, Brazil

3 Department of Pharmacology, School of Medicine of Ribeirão Preto, University of São Paulo, Ribeirão Preto, São Paulo, Brazil cytokines into inflamed joints. This effect is abrogated by administration of the opioid antagonist naloxone.

Keywords Arthritis - Cytokines - Zymosan - Pain · Strontium ranelate

\section{Introduction}

Strontium ranelate (SR) is a compound currently used to treat osteoporosis. SR has been claimed to display the unique characteristic of being an orally active compound to treat osteoporosis by increasing bone formation while also decreasing bone resorption [1]. Treatment with SR was shown to reduce both vertebral and hip fractures in postmenopausal women $[2,3]$.

Similar to bisphosphonates, which are also indicated to treat osteoporosis, SR may provide pain relief. In this regard, we have previously shown that risedronate, a thirdgeneration orally acting bisphosphonate, displays intrinsic analgesic activity in experimental arthritis that is associated to a decrease on the release of tumor necrosis factor- $\alpha$ $(\mathrm{TNF} \alpha)$ and leukotriene $\mathrm{B}_{4}$ into inflamed joints [4]. Reduction of back pain in patients with spinal osteoporosis was described in patients treated with SR. Furthermore, a post hoc analysis of pooled radiological data from the Spinal Osteoporosis Therapeutic Intervention (SOTI) [2] and Treatment of Peripheral Osteoporosis (TROPOS) [3] clinical trials suggests that SR could reduce the progression of spinal osteoarthritis as well as back pain in women with osteoporosis and prevalent spinal osteoarthritis raising the possibility that SR has the potential to be a disease-modifying slow-acting drug in osteoarthritis [5].

Osteoporosis, osteoarthritis as well as rheumatoid arthritis share in common the occurrence of pain and bone changes, 
usually affecting middle-aged women. Osteoclasts are derived from macrophage precursors and exert bone resorption under the influence of cytokines. Coupling of the receptor activator nuclear factor $\kappa-\mathrm{B}$ ligand (RANK-L) to osteoclast receptors increases the differentiation of monocytes into an osteoclast phenotype, inhibit osteoclast apoptosis, while also triggering the activation of mature osteoclasts into bone-resorbing cells [6]. It seems reasonable to postulate that compounds acting on osteoclasts may also act on other bone marrow-derived mononuclear phagocytes, like the type A synoviocytes, which are involved in the pathogenesis of chronic inflammatory arthropathies [7, 8]. Macrophages are being increasingly recognized as participating in the pathogenesis of osteoarthritis [9]. More recently, monocytes from osteoarthritis patients were shown to display increased bone-resorbing activity [10]. Therefore, macrophages, osteoclasts as well as synoviocytes, play a role in inflammatory components of arthritis development, regardless of the causative mechanisms. SR had a protective effect in experimental osteoarthritis that was linked to a reduction of matrix metalloproteinases and interleukin (IL)$1 \beta$ in the synovium [11]. In the present study, we explored the effect of SR on the pain component of experimental arthritis.

\section{Materials and methods}

\section{Animals}

Wistar rats (180-200 g) were provided by the central animal house of the Federal University of Ceará, FortalezaCE, Brazil. Animals were housed in cages (6/cage) in temperature-controlled rooms with a $12 \mathrm{~h}$ light/dark cycle with free access to water and food. At the start of any experiments, rats were 2.5 months of age. All efforts were made to minimize animal suffering and the number of animals used. The protocol was approved by our local ethics committee (Comitê de Ética em Experimental Animal-Faculty of Medicine-Federal University of Ceará number 60/08) that follows the rules of the Brazilian Committee on Animal Experimentation (COBEA).

\section{Assessment of pain behavior}

\section{Articular Incapacitation test}

A group of six rats received a standard intra-articular (i.a.) injection of zymosan ( $1 \mathrm{mg}$ in $50 \mu \mathrm{l}$ total volume), dissolved in sterile saline, into their right knee joints. Control animals $(n=6)$ received saline. Briefly, after zymosan injection, animals were put to walk on a steel rotary drum (30 cm wide $\times 50 \mathrm{~cm}$ diameter) covered with a fine-mesh non-oxidyzable wire screen, which rotates at $3 \mathrm{rpm}$.
Specially designed metal gaiters were wrapped around both hind-paws. After placement of the gaiters, animals were allowed to walk freely for habituation. The right paw was then connected via a simple circuit to a microcomputer data input/output port. The paw elevation time (PET) is the time that during a $60 \mathrm{~s}$ period the inflamed hind-paw is not in contact with the cylinder. This is directly proportional to the articular incapacitation. Results (s/1 min) are reported as the maximal PET that occurs between 3 and $4 \mathrm{~h}$ after injecting zymosan. The articular incapacitation measured is inhibited by classical analgesic compounds leading to the assumption that it reflects joint pain [12].

\section{Paw-pressure test}

Assessment of pain behavior (regarded as joint pain) was done using the electronic pressure-meter nociception paw test by an observer blinded to group allocation. This method captures pain arising distal from the inflamed joint thus probably reflecting central sensitization [13]. Animals were placed in acrylic cages $(12 \times 10 \times 17 \mathrm{~cm}$ high $)$ with a wire grid floor, $15 \mathrm{~min}$ before the beginning of the tests, in a quiet room. Stimulations were performed only when animals were quiet, without exploratory, urination, or defecation movements and not resting on their paws. The electronic pressuremeter consists of a hand-held force transducer fitted with a polypropylene tip (Electronic von Frey aesthesiometer, Insight Equipamentos Científicos Ltda., Brasil). The polypropylene tip was applied perpendicularly to one of the five distal footpads of the right hind-paw. The intensity of the stimulus was automatically recorded when the paw was withdrawn. The test was repeated three times, until less than a $1 \mathrm{~g}$ difference between measurements was obtained. Results were expressed as the mean value of three withdrawal threshold measurements $(\mathrm{g})$.

\section{Osteoarthritis model}

We used the anterior cruciate ligament transection (ACLT) model as an experimental model of osteoarthritis (OA) [14]. Briefly, animals were anesthetized with chloral hydrate and subjected to transection of the anterior cruciate ligament. A sham group was subjected to the same surgical procedure, without transection of the anterior cruciate ligament. Assessment of hypernociception (joint pain) was done using the articular incapacitation and electronic pressure-meter nociception paw tests, as described above.

\section{Assessment of cell influx and cytokines levels in joint exudates}

At $6 \mathrm{~h}$ after injection of the zymosan, the animals were sacrificed under terminal anesthesia, euthanized by cervical 
dislocation, and exsanguinated. The synovial cavity of the knee joints was then washed with $0.4 \mathrm{ml}$ saline containing $10 \mathrm{mM}$ EDTA. The joint washes were collected by aspiration and total cell counts were performed using a Neubauer chamber. After centrifuging $(500 \mathrm{~g} / 10 \mathrm{~min})$, the supernatants were used for measuring the concentrations of TNF$\alpha$, IL-1 $\beta$, and CINC-1/CXCL1, using ELISA. Briefly, 96-well microtiter plates (NUNC-Immuno ${ }^{\mathrm{TM}}$ Plate) were coated overnight at $4{ }^{\circ} \mathrm{C}$ with sheep polyclonal anti-rat TNF$\alpha$, sheep polyclonal anti-rat IL-1 $\beta$, or sheep polyclonal antirat CINC-1, diluted in $50 \mu \mathrm{l}$ PBS buffer. These antibodies were provided by Dr. Steeve Poole (National Institute for Biological Standards and Control, UK). Blocking of nonspecific binding sites was accomplished by incubating plates with PBS containing $2 \% \mathrm{BSA}$ for 90 min at $37{ }^{\circ} \mathrm{C}$. A secondary rabbit biotinylated immunoaffinity-purified antibody was added, followed by incubation for $1 \mathrm{~h}\left(22^{\circ} \mathrm{C}\right)$. Finally, $100 \mu \mathrm{l}$ of avidin-HRP (1:5000 dilution; DAKO A/S, Denmark) was added to each well; after $30 \mathrm{~min}$ the plates were washed and the color reagent OPD (40 $\mu \mathrm{g} /$ well) was added. After $15 \mathrm{~min}$, the reaction was stopped with $1 \mathrm{M} \mathrm{H}_{2} \mathrm{SO}_{4}$ and the O.D. was measured at $490 \mathrm{~nm}$. Cytokine concentration was expressed as $\mathrm{pg} / \mathrm{ml}$.

\section{Drug treatments}

For the pain behavior studies, three groups of six animals subjected to the zymosan-induced arthritis received $30-300 \mathrm{mg} / \mathrm{kg}$ SR (Protos ${ }^{\mathrm{TM}}$-Servier, Brasil) by gavage $30 \mathrm{~min}$ prior to stimulus injection. Control groups (NT) received saline as the vehicle, also by gavage. Naïve animals received intra-articular saline. The experiments to define the best SR dose were done in two independent experiments, using six animals/group in each experiment. For analysis of the effect of SR in pain behavior in an OA model, two groups of six animals received either $300 \mathrm{mg} / \mathrm{kg} / \mathrm{d} \mathrm{SR}$ or saline, by gavage, after $2 \mathrm{~h}$ fasting in the 14th and 16th days following surgery and the analgesia was evaluated using the von Frey test. Similar to what was done in the zymosan arthritis, two other groups subjected to ACLT received either SR (300 mg/ $\mathrm{kg}$ ) or saline per os and had the pain behavior evaluated using the AI test 7 days following ACLT.

Groups received the non-specific opioid receptor antagonist naloxone (Cristália, São Paulo, Brazil-2 mg/ $\mathrm{kg} \mathrm{s.c.)} 30 \mathrm{~min}$ prior to $\mathrm{SR}$ as a strategy to investigate a possible contribution of an opioid-related mechanism SR anti-nociceptive effect. Non-treated groups (NT) received the vehicle.

\section{Statistical analysis}

Results are presented as mean \pm S.E.M. of measurements made on at least six animals in each group. Differences between means were compared using one-way ANOVA followed by Tukey's test; $P<0.05$ was considered as significant.

\section{Results}

\section{Effect of strontium ranelate in the acute cell influx and joint pain in zymosan arthritis}

In order to establish a dose-response curve, we first studied the effect of SR in the zymosan arthritis model. The effect of the oral administration of SR $(30-300 \mathrm{mg} /$ $\mathrm{kg}$ ) in joint pain in zymosan arthritis is shown in Fig. 1a. As reported previously, zymosan injection provokes an increase in the PET, starting $2 \mathrm{~h}$ and peaking between 3 and 4 hlater [12]. Administration of SR (100 and $300 \mathrm{mg} /$ $\mathrm{kg})$ significantly and dose-dependently $(P<0.05)$ reduced
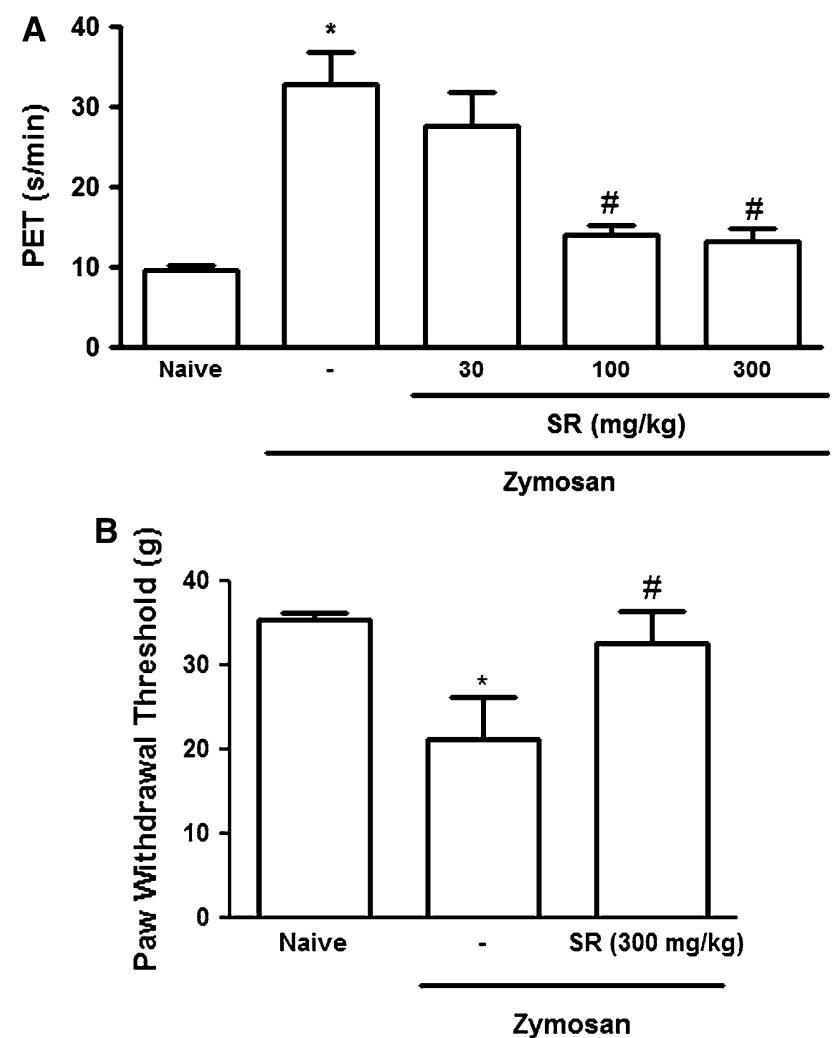

Fig. 1 Effect of strontium ranelate (SR) in pain behavior in acute zymosan arthritis. Rats received $1 \mathrm{mg}$ zymosan or saline intraarticularly. a Articular incapacitation was measured at $4 \mathrm{~h}$ as the increase in paw elevation time (PET) assessed using the rat knee-joint incapacitation test (see text for details) or the paw-pressure test (b). SR or saline (-) were given per os 30 min prior to zymosan. Results are expressed as mean \pm S.E.M of maximal PET or paw withdrawal threshold obtained between 3 and $4 \mathrm{~h}$ of arthritis; $n=6$ animals for each group. ${ }^{*} P<0.05$ compared to naive and ${ }^{\#} P<0.05$ compared to (-) using one-way ANOVA followed by Tukey's test 


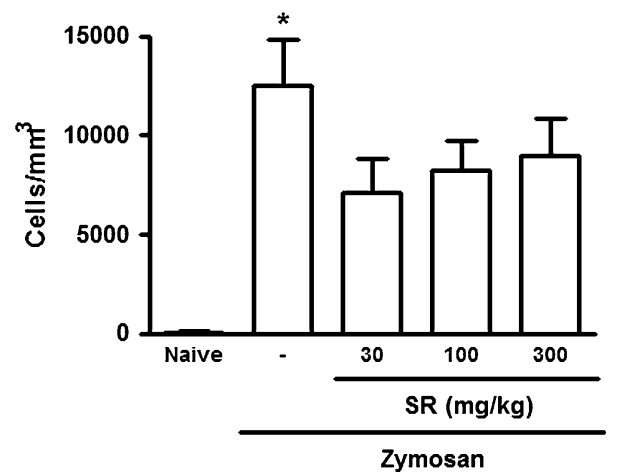

Fig. 2 Effect of strontium ranelate (SR) in cell influx in acute zymosan arthritis. Rats received $1 \mathrm{mg}$ zymosan or saline intraarticularly. Cell influx was assessed in joint exudates $6 \mathrm{~h}$ after zymosan injection. SR or saline (-) were given per os $30 \mathrm{~min}$ prior to zymosan. Results are expressed as mean \pm S.E.M. of total leukocytes; $n=6$ animals for each group. ${ }^{*} P<0.05$ compared to naive using one-way ANOVA followed by Tukey's test

the maximal PET as compared to animals that received the vehicle (NT). The $300 \mathrm{mg} / \mathrm{kg}$ SR dose did also significantly inhibit joint pain assessed using the von Frey method in rats subjected to zymosan arthritis (Fig. 1b). Different from the effect of SR in pain behavior, the cell influx into the joints was not significantly altered by SR administration (Fig. 2). Data are representative out of two experiments. Thus, we decided to use $300 \mathrm{mg} / \mathrm{kg}$ SR in further experiments.

\section{Effect of strontium ranelate in joint pain in an $\mathrm{OA}$ model}

The administration of SR did significantly reduce pain in another group of rats subjected to ACLT, measured using the AI method, as shown in Fig. 3a. Figure 3a shows that the paw withdrawal threshold was significantly and persistently elevated in animals that were subjected to ACLT, as compared to sham-operated animals. At the 14th day, the administration of SR significantly inhibited that pain behavior, measured after 2,4 , and $6 \mathrm{~h}$ of SR administration, as compared to animals that received the vehicle. The analgesic effect of SR subsided in the following (15th) day so that paw withdrawal threshold levels returned to baseline on day 15. Repeating the administration of SR on day 16 restored the analgesic response.

\section{Effect of pre-treatment with naloxone upon the anti-nociceptive activity of strontium ranelate in arthritis}

The administration of naloxone $(2 \mathrm{mg} / \mathrm{kg}) 30 \mathrm{~min}$ before SR (300/mg kg) significantly reversed the analgesic effect
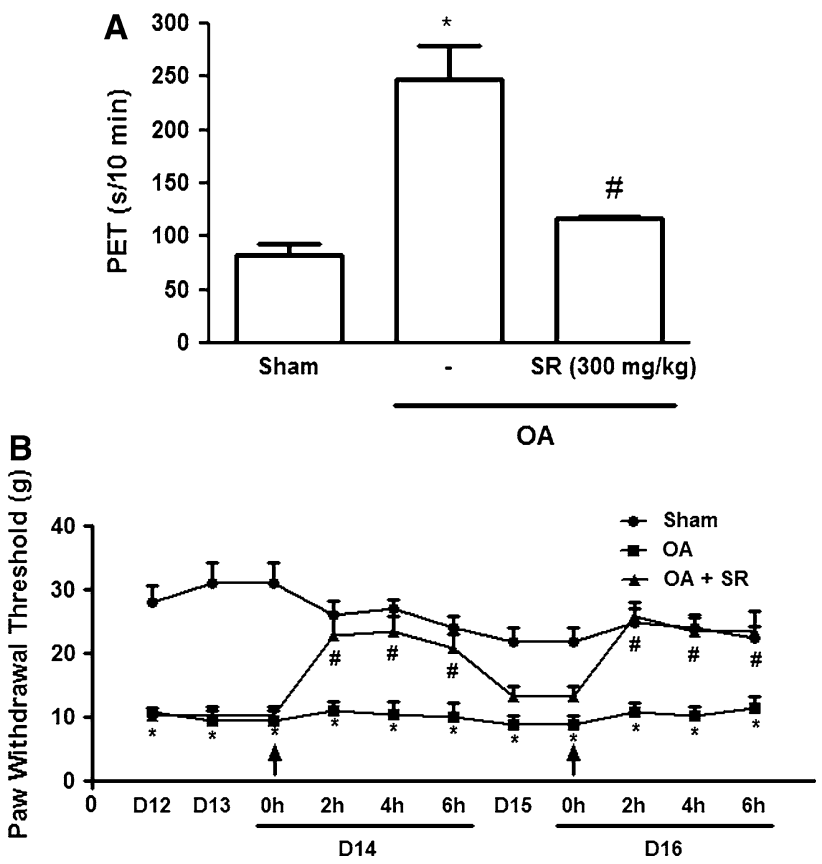

Fig. 3 Effect of strontium ranelate (SR) in pain behavior in an osteoarthritis (OA) model. a Rats were subjected to anterior cruciate ligament $(\mathrm{OA})$ or to a sham procedure. Articular incapacitation was measured as the increase in paw elevation time (PET) assessed using the rat knee-joint incapacitation test (a) or daily over 16 days using the electronic pressure-meter nociception paw test (b). Groups received SR $(300 \mathrm{mg} / \mathrm{kg})$ or saline (-) per os daily from days 1 to 4 (a) or at days 14 and 16 (b). Pain was measured at day four following surgery $4 \mathrm{~h}$ after SR (a) or at baseline and 2, 4, and $6 \mathrm{~h}$ following SR or saline administration (b). Data represent the mean \pm S.E.M. of the PET (a) or mechanical threshold (b); $n=6$ animals/group; $* P<0.05$ compared to sham and ${ }^{\#} P<0.05$ compared to OA using one-way ANOVA followed by Tukey's test

of SR in zymosan arthritis, both using the AI and pawpressure tests, thus suggesting that endogenous opioids contribute to the analgesic effect of SR (Fig. 4a, b). Additionally, naloxone pre-treatment did also reverse SR analgesia in the OA model (Fig. 4c). As a control of this strategy, morphine provided analgesia in both the zymosan and OA models and the co-administration of morphine and naloxone, at the same dose that was used with SR, significantly reversed morphine analgesia.

\section{Effect of strontium ranelate on the release of cytokines in zymosan arthritis}

Joint levels of IL-1ß, TNF $\alpha$, and CINC-1 were greatly increased at $6 \mathrm{~h}$ after zymosan injection. Cytokine levels in the joints of animals subjected to the osteoarthritis model were below detection limit. Administration of SR (300 mg/ $\mathrm{kg})$ significantly $(P<0.05)$ inhibited the increase of TNF $\alpha$ and IL-1 $\beta$ levels but not those of CINC-1 (Table 1). 


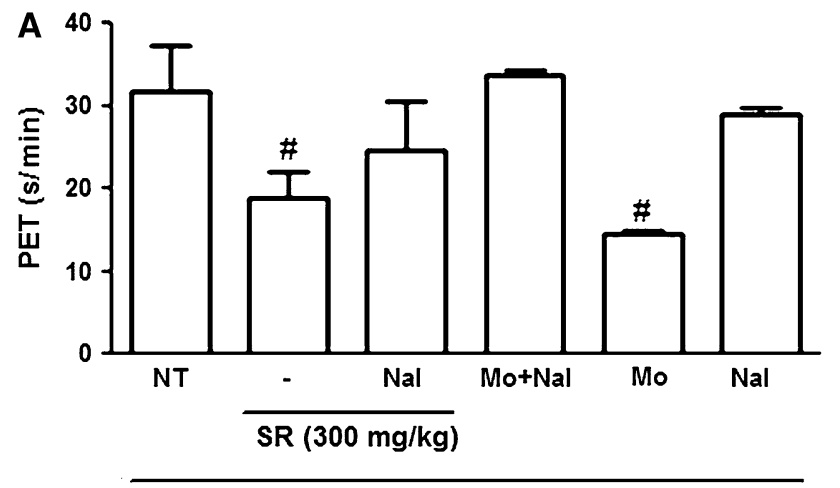

Zymosan
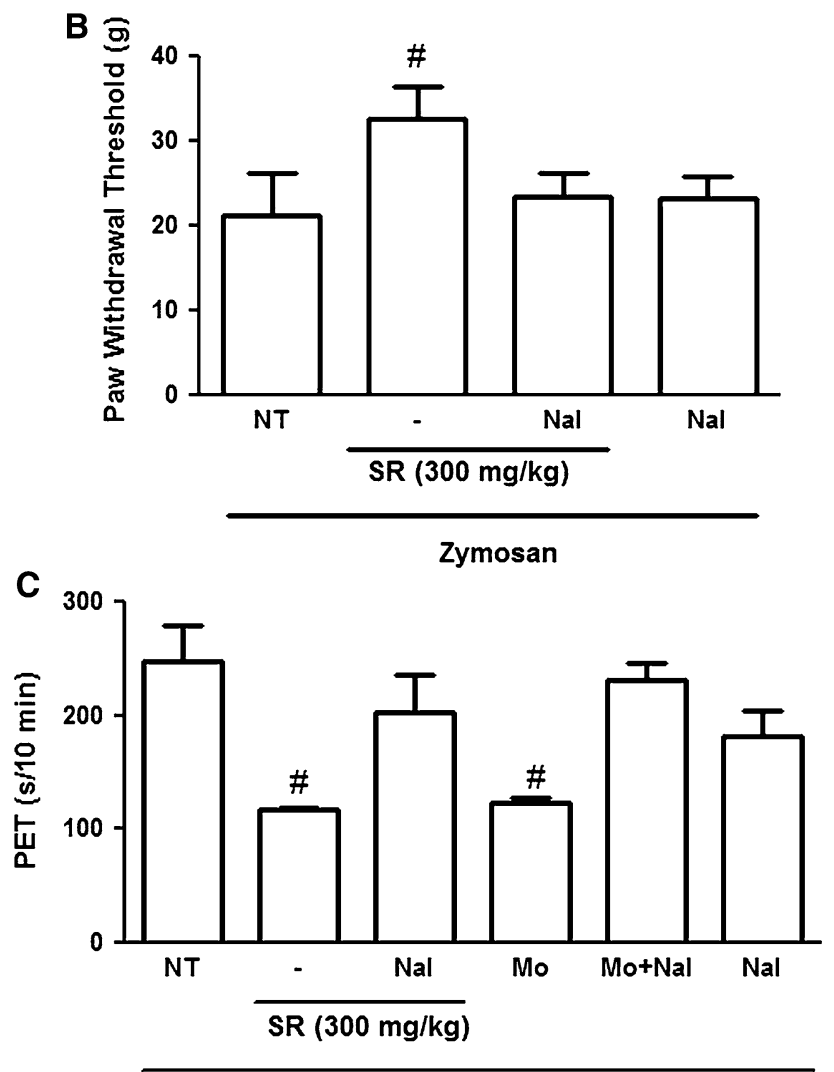

OA

Fig. 4 Effect of naloxone upon the anti-nociceptive activity of strontium ranelate in arthritis. Pain was measured after SR $(300 \mathrm{mg} /$ $\mathrm{kg}$ ) or saline (NT) administration in rats subjected to zymosan arthritis $(\mathbf{a}, \mathbf{b})$ or to an OA model (c) using the articular incapacitation $(\mathbf{a}, \mathbf{c})$ and paw-pressure tests (b). Groups received $2 \mathrm{mg} / \mathrm{kg}$ naloxone prior to $300 \mathrm{mg} / \mathrm{kg}$ SR (SR + Nal), $5 \mathrm{mg} / \mathrm{kg}$ morphine (Mo), $2 \mathrm{mg} / \mathrm{kg}$ naloxone prior to $5 \mathrm{mg} / \mathrm{kg}$ morphine ( $\mathrm{Nal}+\mathrm{Mo}$ ), or $2 \mathrm{mg} / \mathrm{kg}$ naloxone (Nal). Results are expressed as mean \pm S.E.M. of maximal PET or paw withdrawal threshold; $n=6$ animals for each group. $* P<0.05$ compared to NT using one-way ANOVA followed by Tukey's test

\section{Discussion}

This study reveals that SR displays analgesic properties, illustrated by a highly effective inhibition of the pain behavior response in animals subjected to either zymosan- induced or OA arthritis. The analgesia provided by SR is associated with a reduction of cytokine levels released into inflamed joints in zymosan arthritis. Since the co-administration of the non-specific opioid antagonist naloxone reversed SR analgesic effect, an opioid-dependent mechanism is also probably involved.

Apart from having a crucial role in the pathophysiology of inflammatory arthropathies, TNF $\alpha$ promotes hyperalgesia in experimental models of arthritis [15]. We have previously demonstrated that risedronate inhibition of the hypernociceptive response in zymosan arthritis was related to a marked decrease of TNF $\alpha$ release [4]. Coupled to the present results, these two antiosteoporotic compounds, namely risedronate and SR, share an analgesic effect that involves decreasing the production of $\mathrm{TNF} \alpha$ into the inflamed joint.

Experimental data lend support to targeting IL-1 $\beta$ to control inflammatory pain [16]. More recently, it was also shown that SR decrease IL-1 $\beta$ gene expression in the synovium of dogs subjected to an experimental OA model [11]. In line with those data, our results demonstrate a reduction of IL-1 $\beta$ level released into the joint fluid of rats subjected to zymosan arthritis. Levels were measured as early as $6 \mathrm{~h}$ following zymosan injection. At this time, there is virtually no synovial hyperplasia in the synovium opening the possibility that SR is inhibiting IL- $\beta$ production by resident synoviocytes.

TNF induces the liberation of IL-8, another important proinflammatory cytokine [17]. Rats do not express IL-8 but an ortholog cytokine, CINC-1, instead, which plays a major role in cell recruitment during inflammation [18]. Different from what was observed with TNF $\alpha$ and IL-1 $\beta$, SR did not alter joint levels of CINC-1 in zymosan arthritis.

The molecular mechanisms by which SR increases bone mass and strength are not fully understood. It was shown that SR reduces osteoclast activity by disrupting its cytoskeleton and promotes osteoclast apoptosis while enhancing the replication of preosteoblast cells and osteoblast differentiation [19]. This dual effect of SR on mesenchymal (osteoblasts) and bone marrow (osteoclasts)derived cells suggests that other cell types of similar progeny are susceptible to SR action. Type A and type B synoviocytes resemble macrophages (bone marrow progeny) and fibroblasts (mesenchymal progeny), respectively [8]. Those synovial cells, which proliferate during arthritis, are involved in the production of proinflammatory cytokines leading to cartilage degradation and increased bone resorption [8]. SR significantly reduced cytokines release measured at $6 \mathrm{~h}$ of arthritis, while not altering acute cell influx.

In an attempt to further dissect the mechanisms involved in the analgesia promoted by SR, we obtained that the 
Table 1 Effect of strontium ranelate (SR) on the release of cytokines

\begin{tabular}{lllr}
\hline Group & TNF- $\alpha$ & IL-1 $\beta$ & CINC-1 \\
\hline Naive & - & - & $30.2 \pm 0.9$ \\
Zymosan & $68.23 \pm 7.2$ & $924.98 \pm 31.4$ & $136.8 \pm 3.2$ \\
Zymosan + SR & $16.17^{*} \pm 4.3$ & $169.6^{*} \pm 29.13$ & $122.5 \pm 17.7$ \\
\hline
\end{tabular}

Rats received $1 \mathrm{mg}$ zymosan or saline intra-articularly and cytokine levels $(\mathrm{pg} / \mathrm{mL})$ in joint exudates were measured at $6 \mathrm{~h}$ using ELISA. Groups received SR $(300 \mathrm{mg} / \mathrm{kg})$ or saline (-) per os $30 \mathrm{~min}$ prior to zymosan. Naive animals received saline; Data are mean \pm S.E.M. of $\mathrm{n}=6$ animals/group; $* P<0.05$ compared to zymosan using one-way ANOVA followed by Tukey's test combined administration of the opioid antagonist naloxone and SR completely abrogated the analgesia provided by the isolated injection of SR. The decrease in the paw withdrawal threshold is assumed to capture pain arising distal from the injured joint thus reflecting central sensitization. In keeping with this assumption, we have shown previously that morphine provides significant analgesia in both the zymosan and ACLT models [14, 20]. Morphine displays both central and peripheral analgesic effects and the latter is mediated via a nitric oxide pathway [21, 22]. The reversal promoted by naloxone suggests that an endogenous opioid mechanism, whether peripheral or central, is at least in part responsible for SR analgesic effect.

SR was shown to promote apoptosis of rabbit osteoclasts via the calcium-sensing receptor leading to stimulation of a phospholipase $\mathrm{C}$ pathway and NF- $\mathrm{KB}$ translocation to the nucleus [23]. It has also been shown that opioids may act via toll-like receptors leading to NF- $\mathrm{KB}$ activation and opioid antagonists, including naloxone, antagonize this mechanism [24]. It might well be that that SR inhibited the activation of $\mathrm{NF}-\mathrm{KB}$ in resident synoviocytes leading to less inflammation. Naloxone could have provided analgesia via inhibition of NF- $\kappa B$ activation by SR.

In conclusion, our results provide evidence that SR promotes analgesia in both rats and mice subjected to arthritis models. That analgesia is associated with a decrease in the local release of the cytokines IL-1 and TNF- $\alpha$ and does also involve an endogenous opioid component.

Acknowledgments This work was supported by Grants 302218/2014-9 and 459334/2014-0 from CNPq (Conselho Nacional de Desenvolvimento e Tecnológico-Brasil).

\section{References}

1. Marie PJ. Strontium ranelate: a dual mode of action rebalancing bone turnover in favour of bone formation. Curr Opin Rheumatol. 2006;18:S11-5.

2. Meunier PJ, Roux C, Seeman E, Ortolani S, Badurski JE, Spector TD, Cannata J, Balogh A, Lemmel EM, Pors-Nielsen S, Rizzoli R, Genant HK, Reginster JY. The effects of strontium ranelate on the risk of vertebral fracture in women with postmenopausal osteoporosis. N Engl J Med. 2004;350:459-68.
3. Reginster JY, Seeman E, De Vernejoul MC, Adami S, Compston J, Phenekos C, Devogelaer JP, Curiel MD, Sawicki A, Goemaere $\mathrm{S}$, Sorensen $\mathrm{OH}$, Felsenberg D, Meunier PJ. Strontium ranelate reduces the risk of nonvertebral fractures in postmenopausal women with osteoporosis: Treatment of Peripheral Osteoporosis (TROPOS) study. J Clin Endocrinol Metab. 2005;90:2816-22.

4. Carvalho AP, Bezerra MM, Girão VC, Cunha FQ, Rocha FAC. Anti-inflammatory and anti-nociceptive activity of risedronate in experimental pain models in rats and mice. Clin Exp Pharmacol Physiol. 2006;33:601-6.

5. Bruyere O, Delferriere D, Roux C, Wark JD, Spector T, Devogelaer JP, Brixen K, Adami S, Fechtenbaum J, Kolta S, Reginster JY. Effects of strontium ranelate on spinal osteoarthritis progression. Ann Rheum Dis. 2008;67:335-9.

6. Teitelbaum SL. Bone resorption by osteoclasts. Science. 2000;289:1504-8.

7. Edwards JC, Willoughby DA. Demonstration of bone marrow derived cells in synovial lining by means of giant intracellular granules as genetic markers. Ann Rheum Dis. 1982;41:177-82.

8. Bresnihan B. The synovial lining cells in chronic arthritis. Br J Rheumatol. 1992;31:433-5.

9. Berenbaum F. Osteoarthritis as an inflammatory disease (osteoarthritis is not osteoarthrosis!). Osteoarthritis Cartilage. 2012;21:16-21.

10. Durand M, Komarova SV, Bhargava A, Trebec-Reynolds DP, Li K, Fiorino C, Maria O, Nabavi N, Manolson MF, Harrison RE, Dixon SJ, Sims SM, Mizianty MJ, Kurgan L, Haroun S, Boire G, Lucena-Fernandes MF, de Brum-Fernandes AJ. Monocytes from patients with osteoarthritis display increased osteoclastogenesis and bone resorption. The in vitro osteoclast differentiation in arthritis Study. Arthritis Rheum. 2013;65: 148-58.

11. Pelletier JP, Kapoor M, Fahmi H, Lajeunesse D, Blesius A, Maillet J, Martel-Pelletier J. Strontium ranelate reduces the progression of experimental dog osteoarthritis by inhibiting the expression of key proteases in cartilage and of IL-1 $\beta$ in the synovium. Ann Rheum Dis. 2013;72:250-7.

12. Rocha FA, Aragão AG Jr, Oliveira RC, Pompeu MM, Vale MR, Ribeiro RA. Periarthritis promotes gait disturbance in zymosaninduced arthritis in rats. Inflamm Res. 1999;48:485-90.

13. de Mel Leite AC, Teotonio MA, Girão VC, Lima Pompeu MM, de Melo Nunes R, Cunha TM, Pinto AC, de Queiroz Cunha F, Rocha FA. Meniscal transection rather than excision increases pain behavior and structural damage in experimental osteoarthritis in mice. Osteoarthritis Cartilage. 2014;22: 1878-85.

14. Castro RR, Cunha FQ, Silva FS Jr, Rocha FA. A quantitative approach to measure joint pain in experimental osteoarthritisevidence of a role for nitric oxide. Osteoarthritis Cartilage. 2006;14:769-76.

15. Cunha FQ, Poole S, Lorenzetti BB, Ferreira SH. The pivotal role of tumour necrosis factor alpha in the development of inflammatory hyperalgesia. Br J Pharmacol. 1992;107:660-4. 
16. Ferreira SH, Lorenzetti BB, Bristow AF, Poole S. Interleukin-1 beta as a potent hyperalgesic agent antagonized by a tripeptide analogue. Nature. 1988;334:698-700.

17. Bondeson J, Blom AB, Wainwright S, Hughes C, Caterson B, van den Berg WB. The role of synovial macrophages and macrophage-produced mediators in driving inflammatory and destructive responses in osteoarthritis. Arthritis Rheum. 2010;62:647-57.

18. Rocha FA, Silva FS Jr, Leite AC, Leite AK, Girão VC, Castro $\mathrm{RR}$, Cunha FQ. Tadalafil analgesia in experimental arthritis involves suppression of intra-articular TNF release. Br J Pharmacol. 2011;164:828-35.

19. Marie PJ. Strontium ranelate in osteoporosis and beyond: identifying molecular targets in bone cell biology. Mol Interv. 2010;10:305-12.

20. Guerrero AT, Verri WA Jr, Cunha TM, Silva TA, Rocha FA, Ferreira SH, Cunha FQ, Parada CA. Hypernociception elicited by tibio-tarsal joint flexion in mice: a novel experimental arthritis model for pharmacological screening. Pharmacol Biochem Behav. 2006;84:244-51.
21. Ferreira SH, Nakamura M. II-Prostaglandin hyperalgesia: the peripheral analgesic activity of morphine, enkephalins and opioid antagonists. Prostaglandins. 1979;18:191-200.

22. Cunha TM, Roman-Campos D, Lotufo CM, Duarte HL, Souza GR, Verri WA Jr, Funez MI, Dias QM, Schivo IR, Domingues AC, Sachs D, Chiavegatto S, Teixeira MM, Hothersall JS, Cruz JS, Cunha FQ, Ferreira SH. Morphine peripheral analgesia depends on activation of the PI3Kgamma/AKT/nNOS/ NO/KATP signaling pathway. Proc Natl Acad Sci USA. 2010;107:4442-7.

23. Hurtel-Lemaire AS, Mentaverri R, Caudrillier A, Cournarie F, Wattel A, Kamel S, Terwilliger EF, Brown EM, Brazier M. The calcium-sensing receptor is involved in strontium ranelate-induced osteoclast apoptosis. New insights into the associated signaling pathways. J Biol Chem. 2009;284:575-84.

24. Stevens CW, Aravind S, Das S, Davis RL. Pharmacological characterization of LPS and opioid interactions at the toll-like receptor 4. Br J Pharmacol. 2013;168:1421-9. 